\title{
Workload and injury incidence in elite football academy players
}

\section{Barthélémy Delecroix, Benoit Delaval, Brian Dawson, Serge Berthoin \& Gregory Dupont}

To cite this article: Barthélémy Delecroix, Benoit Delaval, Brian Dawson, Serge Berthoin \& Gregory Dupont (2019): Workload and injury incidence in elite football academy players, Journal of Sports Sciences, DOI: 10.1080/02640414.2019.1584954

To link to this article: https://doi.org/10.1080/02640414.2019.1584954

\section{冓 Published online: 01 Mar 2019.}

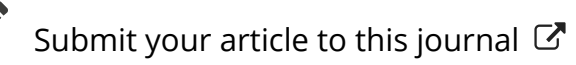

View Crossmark data $\nearrow$ 


\title{
Workload and injury incidence in elite football academy players
}

\author{
Barthélémy Delecroix ${ }^{\mathrm{a}}$, Benoit Delaval ${ }^{\mathrm{b}}$, Brian Dawsonc, Serge Berthoin ${ }^{\mathrm{a}}$ and Gregory Dupont ${ }^{\mathrm{d}}$ \\ aUniv. Lille, Univ. Artois, Univ. Littoral Côte d'Opale, EA 7369 - URePSSS - Unité de Recherche Pluridisciplinaire Sport Santé Société, F-59000 Lille, \\ France; ' ${ }^{b}$ Adaptations physiologiques à l'exercice et réadaptation à l'effort, Université de Picardie Jules Verne, Amiens, France; 'School of Human

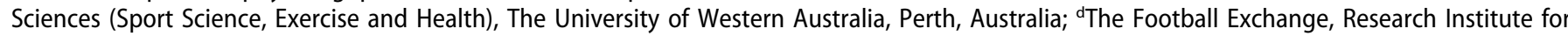 \\ Sport and Exercise Sciences, Liverpool John Moores University, Liverpool, UK
}

ABSTRACT

The aim of this study was to prospectively analyse the relationship between workloads and injury in elite football academy players. Elite football academy players $(n=122)$ from under-19 (U19) and under21 (U21) of a professional football team competing in UEFA European Cups were followed during 5 seasons. Injuries were collected and absolute workload and workload ratios (4-weeks, 3-weeks, 2-weeks and week-to-week) calculated using a rolling days method with the help of the session Rate of Perceived Exertion. There was no association between absolute workload or workload ratio with the injury incidence in the U19. In the U21, the level of cumulative absolute workloads during 3-weeks $(R R=1.39, p=0.026)$ and during 4-weeks $(R R=1.40, p=0.019)$ were associated with an increase in injury. There was no association between workload ratio and injury in U21. The significant link between high cumulated 3-weeks and 4 weeks workloads and injury in U21 confirmed the requirement to monitor the internal subjective workload in U21 in order to prevent injury. Further studies exploring the relationships between workload and injury are required in football academy.
ARTICLE HISTORY

Accepted 14 January 2019

\section{KEYWORDS}

Training; Academy; Team Sport; Injury prevention

\section{Introduction}

Mean injury incidence (match and training) across seven UEFA clubs during seven seasons was reported as eight injuries per 1,000 hours of exposure, which corresponds to 50 injuries per season in a team of 25 players, or two injuries per player per season (Ekstrand, Hagglund, \& Walden, 2011a). This injury incidence is 1,000 times higher than in typical industrial occupations considered as highly risked (Drawer and Fuller, 2002). During the 2012 Olympics, the football competition represented the highest level of injury, with $35.2 \%$ of total number of injuries during the Olympics (Engebretsen et al., 2013). This high injury incidence highlights the importance of injury prevention in elite football.

According to the model of van Mechelen, Hlobil, and Kemper (1992) about the prevention of sports injuries, once the injury incidence and severity have been evaluated through epidemiological studies, the second step to prevent injury risk is to identify the risk factors and injury mechanisms. The third step is to introduce measures that are likely to reduce the future risk and/or severity of injuries. The last step is characterised by assessing the effect of the measures by repeating the first step (van Mechelen et al., 1992). According to this model, several injury risk factors have been identified. In a survey, McCall et al. (2014a) reported that elite football medicine/science practitioners considered previous injury as the most important injury risk factor (121 points of importance on a score of 132). In their systematic review, McCall et al. (2014b) confirmed the practitioners' perceptions: previous injury was the injury risk factor with the highest level of scientific evidence (level 2++ according to the system for graded recommendations guidelines published in British Medical Journal) (Harbour \& Miller, 2001). A previous hamstring, calf, groin or knee injury increases two to three times the risk to sustain a new injury in the same body part during the following season (Hagglund, Walden, \& Ekstrand, 2013). A previous injury also increases the overall injury risk, and not only in the previously injured body part (hazard ratio $=2.7$, Cl95\% 1.7 to 4.3) (Hagglund, Walden, \& Ekstrand, 2006). As a previous injury is a non-modifiable internal injury risk factor, it is important to prevent initial injuries which occur during the youth academy period. The fact to have already been injured during this period would become a non-modifiable risk factor in their future professional career. Moreover, during an injury period, youth players do not have the same training protocol, it could represent an additional gap to bridge in their improvements. Several studies examined the injury incidence in elite youth football academy. In a systematic review of literature, Pfirrmann, Herbst, Ingelfinger, Perikles, and Tug (2016) reported, in youth academies, an overall injury incidence from 2.0 to 19.4 injuries per 1,000h of exposition and a training injury incidence in youth academies from 3.7 to 11.4 injuries per 1,000h of training. For the last year spent in the academy, the overall injury incidence of U18 and U19 (between 6.8 and 10 per 1,000h of exposition) (Nilsson, Ostenberg, \& Alricsson, 2016; Renshaw \& Goodwin, 2016) is comparable to the one reported in elite professional football players (7.6 injuries per $1,000 \mathrm{~h}$ of exposition) (Ekstrand, 
Hagglund, Kristenson, Magnusson \& Walden, 2013). These results concerning the high injury incidence in youth football academy highlights the needs to identify injury risk factors with this population in order to implement injury prevention strategies, especially to reduce the risk to sustain a first injury. Although a few studies have already dealt on the identification of the risk factors and injury prevention in youth academy (Bowen, Gross, Gimpel, \& Li, 2017), most of the studies dealt on high-level professional players (Ekstrand, Hagglund, \& Walden, 2011b; Hagglund et al., 2013).

In their survey, McCall et al. (2014a) reported that the practitioners considered the fatigue ( 105 points of importance on a maximal score of 132) as the second most important injury risk with professional football players. Fatigue could come from the repetition of training and matches. Several studies found a significant association between workload and injury incidence among professional football players (Jaspers, Brink, Probst, Frenken, \& Helsen, 2017; Lu, Howle, Waterson, Duncan, \& Duffield, 2017; Malone et al., 2017). Two reviews of literature concluded that internal/subjective tools were more sensitive and related to injury incidence than external and/or objective tools (Jones, Griffiths, \& Mellalieu, 2017; Saw, Main, \& Gastin, 2016). Jones et al. (2017) included 21 studies evaluating the association between internal workload and injury incidence in sports in a systematic review of literature.The majority (90\%) of these studies concerned team sports. The authors concluded that there was a moderate evidence that the internal workload was associated with injury incidence. In professional football, Malone et al. (2017) identified that an absolute workload calculated with SRPE higher than 1,500 arbitrary units (A.U.) was associated with an elevated injury risk, and that an acute:chronic workload ratio calculated with the SRPE between 1.00 and 1.25 was associated with a lower injury incidence in elite football players. In youth elite football players, one study identified an association between the one week absolute workload calculated using the session Rate of Perceived Exertion (sRPE), using a modified perception scale (Borg, CR-10) and the injury incidence $(\mathrm{OR}=1.01,95 \% \mathrm{Cl} 1.00$ to 1.06 ) (Brink et al., 2010). However, in this study, the workload was calculated only for 1 week, while associations between external workload and injury incidence during 2,3 or 4 cumulative weeks and $A: C$ ratios have been identified (Bowen et al., 2017). To our knowledge, no study aimed at evaluating the association of absolute internal workload during several weeks, and acute:chronic internal workload ratio and injury in a elite football academy. Therefore, the aim of this study is to analyse the relationships between several combinations of internal workload using the SRPE and the injury among football players in an elite football academy.

\section{Materials and methods}

\section{Subjects}

One hundred twenty-two elite young football players (height: $178.6 \pm 6.8 \mathrm{~cm}$; body mass: $70.9 \pm 7.3 \mathrm{~kg}$ ) from $\mathrm{U} 19$ ( $\mathrm{n}=52$; age: $16.8 \pm 0.9$ ) and $U 21$ ( $n=70$; age: $20.1 \pm 0.3$ ) squads of a football academy in an elite football club playing in first French League and taking part regularly in European competitions were followed during four and five seasons respectively. All players from the U19 and the U21 squads were included in the study. The players lived in the academy. If a player joined the team during the observational period, he was included from the date he joined the team. A player who left the team during the observational period was excluded from the study from the date he left the team. If a player was already injured at the start of data collection, he was included in the study but this injury was excluded (Fuller et al., 2006). All players were informed and consented to take part in the study. This study was conducted in accordance with the local ethical committee on biomedical research (CCTIRS\#10,544) and the standards of the declaration of Helsinki.

\section{Methodology}

This study was a prospective cohort study. An injury was defined, in accordance with the FIFA consensus, as any physical complaint sustained by a player that resulted from a football match or football training, that made the player unable to participate in future football training or a match (Fuller et al., 2006).

The workload was calculated by the sRPE method. This method is valid for its use with athletes and football players (Foster, 1998; Impellizzeri, Rampinini, Coutts, Sassi, \& Marcora, 2004). Players were instructed to rate the global intensity of all sessions and matches using a modified category ratio scale going from 0 to 10 based on the scale developed by Borg, Hassmen, and Lagerstrom (1987) by answering the following question: "How was your workout?". The sRPE was collected 30 minutes after completion of the session/match by a sport clinician working in the club responsible for the collection of the data. The players were isolated to answer in order not to be influenced by other players. Workload, expressed in arbitrary units $(A U)$ was calculated by multiplying the perceived intensity by the session or match duration (Foster et al., 2001); all training sessions and all matches were included. All the training sessions and matches were on natural grass. The workload was calculated on a daily basis with the methods of rolling days blocks (everyday, a new workload was calculated based on the preceding days) (Bowen et al., 2017; Hulin, Gabbett, Lawson, Caputi, \& Sampson, 2016). The absolute workload was the sum of the load for the last 7 days (oneweek workload), 14 days (2-weeks workload), 21 days (3-weeks workload) and 28 days (4-weeks workload) were calculated. To determine $A: C$ ratios, the one-week workload was divided by the total workload of the last 28 days, divided by 4 for the 4-weeks A:C ratio (formula: one-week workload/(last 28 days workload/4)), the total load of the last 21 days divided by 3 for the 3-weeks A:C ratio (one-week workload/(last 21 days workload/3)) and the total load of the last 14 days divided by 2 for the 2 weeks A:C ratio (one-week workload/(last 14 days workload/2)) (Malone et al., 2017). The week-to-week load changes were also calculated by dividing the 1-week load by the accumulated load of the previous 7 days. The workload was known by the practitioners who could use the data to regulate the workload. In U19, the group (and not individual) workload was regulated on a weekly basis by the practitioners. The workload was analysed in the end of each week and the practitioners aim was to reach a weekly mean of 2,500 A.U, 
because they considered it was the optimal workload to reduce the injury risk while improving players fitness qualities. The data were not taken into account in U21 to regulate the workload.

\section{Statistical analysis}

A Poisson regression analysis was performed with IBM SPSS Statistics Version 20 for the 1-week, 2-weeks, 3-weeks and 4-weeks absolute workload and the $\mathrm{A}: \mathrm{C}$ workload ratios to assess the link between these factors and injury incidence and calculate relative risk (RR). The absolute workload and the $A: C$ workload ratios were log-transformed when the scores were not normally distributed.

The daily probability to sustain an injury was calculated by dividing the number of injuries by the number of days of observation, multiplied by 100 .

\section{Results}

A total of 122 players have been followed during the period of observation. The number of players in each squad, season by season, are described in Table 1. In U19 category, a total 52 players were followed (24 players were followed during one season, 26 players were followed during two seasons, 2 players were followed during 3 seasons). In U21 category, a total of 70 players were followed (41 players were followed during one season, 16 players were followed during 2 seasons, 8 players were followed during 3 seasons, 4 players were followed during 4 seasons and one player was followed during the 5 seasons of observation). It represents a total of 200 player-seasons, 17,778 days in the $U 19$ and of 26,672 days in the $\mathrm{U} 21$ were recorded.

A total of 182 injuries were recorded in the U19 category (119 non-contact +63 contact injuries) and of 307 injuries (215 non-contact +92 contact injuries) were recorded in the U21 category. It represents a global injury incidence of 7.6 injuries per 1,000h of exposition for the U19 and of 9.6 injuries per $1,000 \mathrm{~h}$ of exposition for the U21. The daily probability to sustain an injury was $1.02 \%$ in U19 and $1.15 \%$ in U21.

In U19, the mean weekly workload was $2046 \pm 705 \mathrm{AU}$; the mean 2 weeks workload was $3813 \pm 1291 \mathrm{AU}$; the mean 3 weeks workload was $5501 \pm 1831 \mathrm{AU}$ and the mean 4 weeks absolute workload was $7104 \pm 2334$ AU. No link was found between absolute workload, cumulative absolute workload ( 2 weeks, 3 weeks, 4 weeks) and global, non-contact or contact injuries with U19 players. These results are described in Table 2. No link was found between none of the A:C workload ratio and global, non-contact and contact injuries with U19 players, as described in Table 3.

Table 1. Number of players observed in U19 and U21 during the 5 seasons of observation.

\begin{tabular}{ccc}
\hline & $\begin{array}{c}\text { Number of players observed in } \\
\text { U19 }\end{array}$ & $\begin{array}{c}\text { Number of players observed in } \\
\text { U21 }\end{array}$ \\
\hline $2012-2013$ & $\mathrm{X}$ & 21 \\
$2013-2014$ & 18 & 26 \\
$2014-2015$ & 16 & 24 \\
$2015-2016$ & 23 & 28 \\
$2016-2017$ & 25 & 19 \\
\hline
\end{tabular}

Table 2. Relative risk RR ( $95 \%$ confidence interval) and p-value for an increase in cumulative workload for the last 7 days ( 1 week), 14 days ( 2 weeks), 21 days ( 3 weeks) and 28 days (4 weeks) in the U19 age category.

\begin{tabular}{lcc}
\hline & $\mathrm{RR}$ & \\
\hline 1 week workload & $(95 \% \mathrm{Cl})$ & $\mathrm{p}$ \\
\hline 2 weeks cumulative workload & 1.11 & 0.44 \\
3 weeks cumulative workload & $(0.84-1.50)$ & 0.85 \\
4 weeks cumulative workload & 1.03 & 0.82 \\
& $(0.77-1.38)$ & 0.97 \\
& $(0.74-1.28)$ & 0.97 \\
\hline
\end{tabular}

Table 3. Relative risk RR (95\% confidence interval) and $p$-value for an increase in Acute:Chronic workload with a chronic workload calculated over the last the last 28 days ( 4 weeks), the last 21 days ( 3 weeks), the last 14 days ( 2 weeks) and the week to week changes in workload in the U19 age category.

\begin{tabular}{lcc}
\hline & $\mathrm{RR}$ & \\
& $(95 \% \mathrm{Cl})$ & $\mathrm{p}$ \\
\hline 4 weeks A:C workload & 1.01 & 0.73 \\
3 weeks A:C workload & $(0.96-1.07)$ & \\
& 1.00 & 0.91 \\
2 weeks A:C workload & $(0.95-1.06)$ & 0.82 \\
Week to week workload changes & 0.99 & \\
& $(0.90-1.09)$ & 0.93 \\
& 1.00 & \\
\hline
\end{tabular}

In U21, the mean weekly workload was $1979 \pm 666 \mathrm{AU}$; the mean 2 weeks workload was $3783 \pm 1211 \mathrm{AU}$; the mean 3 weeks workload was $5497 \pm 1740 \mathrm{AU}$ and the mean 4 weeks workload was $7145 \pm 2254 \mathrm{AU}$. The results concerning the link between absolute workload and global, non-contact and contact injuries in $\mathrm{U} 21$ are described in Table 4. An association was found between the cumulative 3 weeks absolute workload and injury incidence $(R R=1.39, p=0.026)$ and between the cumulative 4 weeks absolute workload and injury incidence ( $R R=1.40, p=0.019)$. There was no association between the $A: C$ workload ratio and the injury incidence with U21 players. The results are described in Table 5 .

\section{Discussion}

The aim of this study was to analyse the relationship between workload and injury incidence in elite football academy players. The main findings showed that there was no association between absolute or A:C workload ratio with U19 players, while there was an association between 3 weeks and 4 weeks cumulative absolute workload with U21 players.

Table 4. Relative risk RR (95\% confidence interval) and p-value for an increase in cumulative workload for the last 7 days ( 1 week), 14 days ( 2 weeks), 21 days ( 3 weeks) and 28 days (4 weeks) in the U21 age category.

\begin{tabular}{lcc}
\hline & $\mathrm{RR}$ & \\
& $(95 \% \mathrm{Cl})$ & $\mathrm{p}$ \\
\hline 1 week workload & 1.18 & 0.19 \\
2 weeks cumulative workload & $(0.92$ to 1.52$)$ & 0.076 \\
3 weeks cumulative workload & 1.28 & \\
4 weeks cumulative workload & $(0.97$ to 1.69$)$ & 0.026 \\
& $(1.39$ & 0.01 to 1.84$)$ \\
& 1.40 & \\
\hline
\end{tabular}


Table 5. Relative risk RR ( $95 \%$ confidence interval) and p-value for an increase in Acute:Chronic workload with a chronic workload calculated over the last the last 28 days (4weeks), the last 21 days ( 3 weeks), the last 14 days ( 2 weeks) and the week to week changes in workload in the U21 age category.

\begin{tabular}{lcc}
\hline & $\mathrm{RR}$ & \\
& $(95 \% \mathrm{Cl})$ & $\mathrm{p}$ \\
\hline 4 weeks A:C workload & 0.89 & 0.34 \\
& $(0.71$ to 1.13$)$ & \\
3 weeks A:C workload & 0.88 & 0.37 \\
& $(9.66$ to 1.16$)$ & \\
Weeks A:C workload & 0.86 & 0.47 \\
Week to week workload changes & $(0.58$ to 1.29$)$ & \\
& 1.00 & 0.91 \\
\hline
\end{tabular}

In the current study, the overall injury incidence was 7.6 injuries per 1,000h of exposition with U19 and 9.6 injuries per $1,000 \mathrm{~h}$ of exposition with U21 players. These results confirm those of previous studies with an overall injury incidence between 6 and 10 injuries per 1,000h of exposition with players in U18 and U19 categories (Nilsson et al., 2016; Renshaw \& Goodwin, 2016). This injury incidence is also close to the injury incidence of elite professional football teams (8 injuries per 1,000h of exposition) (Ekstrand, Hagglund, \& Walden, 2011a). When transforming these results into daily probability, the overall daily probability to sustain an injury in U19 is $1.02 \%$ per player and in U21 is $1.15 \%$ per player. The daily probability to sustain an injury per player highlights that even if the injury incidence is very high compared to other activities (Ekstrand, 2013), the daily probability to sustain an injury in a youth academy is low, being approximately $1 \%$.

No link between absolute workload, A:C workload ratio and injury incidence was found for the U19. These results about the lack of significant relationship between absolute workload and the occurrence of injury are different of a previous study led by Brink et al. (2010), who found an association between internal workload calculated using the sRPE and the injury incidence. However, the methodology used are different. First of all, Brink et al. analysed the sum of the workload week after week, while in the current study, a rolling days method was used to analyse the workload day after day. This is a major difference between the two studies as an injury at the beginning of the week or in the end of the week could lead to big changes in the weekly workload with Brink et al.'s methodology (2010). In the study led by Brink et al. (2010), an odd ratio was calculated, while in the current study, a Poisson regression was used, providing a relative risk. The injury incidence in Brink et al. study (2010) (37.55 per 1,000h of match and 11.14 per $1,000 \mathrm{~h}$ of training) was higher than the one in the present study (7.6 in U19 and 9.6 in U21). The probability to find a significant association between a potential risk factor and an event depends on the event frequency. It means that the higher the injury incidence is, the higher the probability to find a significant statistical association is (Bahr and Holme, 2003). The method to calculate the workload was not exactly the same as the authors used a 15-point scale to rate the perceived intensity and multiply the perceived exertion by the number of hours of practice while a 10-point scale was used in the present study and the exertion was multiplied by the number of minutes of practice. It is therefore difficult to compare the workload data range width while the data range width of the independent factor modifies the results of a regression (Salgueiro Da Silva \& Seixas, 2017). Another difference in the results could be explained by a different definition of injury, as Brinks et al. (2010), defined the injury as any physical complaint sustained by a player that results from a soccer match or soccer training and leading to time loss or medical attention. In the present study, only the complaint leading to time loss were taken into account. Given the very low odd ratio ( $\mathrm{OR}=1.01,95 \% \mathrm{Cl} 1.00$ to 1.02 ) reported by Brink et al. (2010), these changes in the methodology could explain the absence of association in the current study and the differences between the two studies.

In the U21, no association was found between none of the A:C workload while an association was found between the cumulative absolute 3 weeks and 4 weeks workload and the injury incidence. In the current study, no association has been found with none of the workload calculated over the last 7 days (absolute 1 week workload or A:C workload ratio). These results does not allow to identify a link between the internal A:C workload ratios calculated with SRPE and injury incidence with academy players while this association has been identified with professional players (Malone et al., 2017). In professional football, an A:C ratio between 1.00 and 1.25 has been identified as an injury protective factor (Malone et al., 2017). An elevated $A: C$ workload ratio is the result of the combination of a low chronic workload and a high acute workload (Blanch \& Gabbett, 2016). It means that a low chronic workload or spikes in the workload calculated with SRPE should be avoided in elite level football players in order to reduce the injury incidence (Blanch \& Gabbett, 2016). Jaspers et al. (2018) identified that an elevated workload calculated with the help of sRPE during two weeks was associated with an elevated incidence of overuse injury with elite football players while a medium workload during four weeks was associated with a decrease in injury incidence in comparison with a low workload calculated with SRPE. This result indicates that a minimum level workload should be necessary to avoid an increase in injury risk, and that a chronic workload too low could be an injury risk factor among professional football players. These results highlight the association between injury incidence and acute and chronic workload calculated with SRPE in professional football. This association has not been found in the present study with academy players. Differences between players playing in a youth football academy and professional football players playing in European competitions could be explained by differences in the changes in acute workload. Large changes in workload sustained by professional football players could occur during the congested schedule with two to three-games per week. The schedule in youth category seems to be more regular without congested periods, leading to smaller changes in the acute workload. These differences in the competitions schedules could explain the absence of association between $\mathrm{A}: \mathrm{C}$ workload ratio and injury incidence in the $\mathrm{U} 19$ and $\mathrm{U} 21$ age categories.

The difference in results between U19 and U21 in the present study could be explained in part by the smaller number of injuries recorded in U19 compared to U21 (182 vs 307), which is explained by a lower incidence (7.6 vs 9.6) and shorter period of observation in U19 in comparison with the U21 (4 seasons vs 5 seasons). There was a similar proportion of non-contact injuries between U19 and U21 (65\% in U19 vs 
$71 \%$ in U21), but a lower number of non-contact injuries recorded in U19 (119 vs 215), which also could explain the absence of association in U19 as non-contact injuries are considered easier to prevent than contact injuries (Gabbett et al., 2010). As explained in the introduction, a previous injury is the strongest injury risk factor. In future studies, it may be interesting to evaluate the effect of a previous injury on the ability of a player to sustain high workload, as the present results indicate that older players (U21) are more sensitive to high workload, which may be linked to a higher proportion of previously injured players with older players.

This study presents some limitations. First of all, the current study identified an association between absolute workload and injury incidence with players in a football academy but it does not necessarily mean that there is a causal connection between workload and injury incidence (Bahr, 2016). Although very complicated to implement in the real high-level sport world, other studies and randomised controlled trials should be assessed to analyse the effect of a controlled workload on the injury incidence, in an isolated way, to confirm a causal connection (Bahr, 2016). As a cohort study, the design represents a limit. The observation of the players means that the results are influenced by players sustaining several injuries and as such are considered as repeated independent observations while these injuries are multifactorial and are linked to a lot of factors dependent of the player observed, as, for example, the ability to cope with very high load and/or to large variations in workload. One of the limits of this study is the low injury incidence in this study with only 182 injuries for 17,778 days of observation in U19 and 372 injuries for 26,672 days of observation in $\mathrm{U} 21$, representing a daily probability to sustain an injury of $1.02 \%$ in $U 19$ and of $1.15 \%$ in U21. This low probability could explain in part the absence of statistical association in U19 as a low occurrence of an event reduces the probability to find an association between this event and an independent factor (Bahr and Holme, 2003). Another limit of the study concerns the practitioners who recorded the data. If they adapted the workload according to the data recorded to protect some players with very high of low workloads, it would impact the results. This limit could also partly explain the absence of results in U19 compared to the results in U21. In $\mathrm{U} 19$, the workload was regulated on a weekly basis by the practitioners. The objective for the practitioners in U19 was to reach a mean weekly group workload of 2,500 A.U., and was analysed in the end of each week to decide how to manage the group workload in the following week. It could explain why the workload is not associated with the injury incidence in U19. In U21, the data were known by the practitioners but not used to regulate the workload, which could partly explain the differences in the results between the two categories.

Despite these limits, this study presents some interesting strengths. First of all, to our knowledge, this is the first study with elite football academy players analyzing the associations of multiple combinations of internal absolute workload and workload ratios with injury incidence.

With 122 players followed and 200 player-seasons, the cohort of this study was large compared to other studies in the same topic. It is, to our knowledge, the first longitudinal study concerning young football players led during a period as long as five full seasons. The players followed were football players from an elite football academy. It means that there was a very good control about the workload with no missing data and a very good control of the outside activities of the players as most of the players were staying in the academy. It gives a very high level of confidence to the recorded workload.

\section{Conclusion}

In conclusion, the results of this study indicated that the internal workload calculated using the sRPE was not associated with injury incidence in U19. In the U21 category, the absolute workload cumulated during 21 or 28 days is positively associated with the injury incidence. This result indicates that practitioners working with young football players could calculate the internal workload and use the SRPE during their late years of academy in order to potentially reduce the injury incidence. Further studies are required in these age categories to analyse these associations.

\section{Acknowledgments}

The authors thank all the players who took part in the study.

\section{Disclosure statement}

The authors report no conflict of interest.

\section{References}

Bahr, R. (2016). Why screening tests to predict injury do not work and probably never will: A critical review. British Journal of Sports Medicine, 50, 776-780.

Bahr, R., \& Holme, I. (2003). Risk factors for sports injuries A methodological approach. British Journal of Sports Medicine, 37, 384-392.

Blanch, P., \& Gabbett, T. J. (2016). Has the athlete trained enough to return to play safely? The acute: Chronicworkload ratio permits clinicians to quantify a player's risk of subsequent injury. British Journal of Sports Medicine, 50, 471-475.

Borg, G., Hassmen, P., \& Lagerstrom, M. (1987). Perceived exertion related to heart rate and blood lactate during arm and leg exercise. European Journal of Applied Physiology and Occupational Physiology, 56, 670-685.

Bowen, L., Gross, A. S., Gimpel, M., \& Li, F. X. (2017). Accumulated workloads and the acute: Chronicworkload ratio relate to injury risk in elite youth football players. British Journal of Sports Medicine, 51, 452-459.

Brink, M. S., Visscher, C., Arends, S., Zwerver, J., Post, W. J., \& Lemmink, K. A. P. M. (2010). Monitoring stress and recovery: New insights for the prevention of injuries and illnesses in elite youth soccer players. British Journal of Sports Medicine, 44, 809-815.

Drawer, S, \& Fuller, C.W. (2002). Evaluating the level of injury in english professional football using a risk based assessment process. British Journal Of Sports Medicine, 36, 446-451.

Ekstrand, J. (2013). Keeping your top players on the pitch: The key to football medicine at the professional level. British Journal of Sports Medicine, 47, 723-724.

Ekstrand, J., Hagglund, M., \& Walden, M. (2011a). Injury incidence and injury patterns in professional football: The UEFA injury study. British Journal of Sports Medicine, 45, 553-558.

Ekstrand, J., Hagglund, M., \& Walden, M. (2011b). Epidemiology of muscle injuries in professional football (soccer). American Journal of Sports Medicine, 39, 1226-1232.

Ekstrand, J., Hagglund, M., Kristenson, K, Magnusson, H, \& Walden, M. (2013). Fewer ligament injuries but no preventive effect on muscle injuries and 
severe injuries: an 11-year follow-up of the UEFA Champions League injury study. British Journal of Sports Medicine, 47, 732-737.

Engebretsen, L, Soligard, T, Steffen, K, Alonso, J.M, Aubry, M, Budgett, R, Dvorak, J, Jegathesan, M, Meeuwisse, W.H, Mountjoy, M, Palmer-Green, D, Vanhegan, I, \& Renström, P.A. (2013). Sports injuries and illnesses during the london summer olympic games 2012. British Journal Of Sports Medicine, 47, 407-414.

Foster, C. (1998). Monitoring training in athletes with reference to overtraining syndrome. Medicine \& Science in Sports \& Exercise, 30, 1164-1168.

Foster, C., Florhaud, J. A., Franklin, J., Gottschall, L., Hrovantin, L. A., Parker, S., ... Dodge, C. (2001). A new approach to monitoring exercise training. Journal of Strength and Conditioning Research, 15, 109-115.

Fuller, C. W., Ekstrand, J., Junge, A., Andersen, T. E., Bahr, R., Dvorak, J., ... Meeuwisse, W. H. (2006). Consensus statement on injury definitions and data collection procedures in studies of football (soccer) injuries. British Journal of Sports Medicine, 40, 193-201.

Gabbett, T. J. (2010). The development and application of an injury prediction model for noncontact, soft-tissue injury in elite collision sport athletes. Journal of Strength and Conditioning Research, 24, 2593-2603.

Hagglund, M., Walden, M., \& Ekstrand, J. (2006). Previous injury as a risk factor for injury in elite football: A prospective study over two consecutive seasons. British Journal of Sports Medicine, 40, 767-772.

Hagglund, M., Walden, M., \& Ekstrand, J. (2013). Risk factors for lower extremity muscle injury in professional soccer. American Journal of Sports Medicine, 41, 327-335.

Harbour, R., \& Miller, J. (2001). A new system for grading recommendations in evidence based guidelines. British Medical Journal, 323, 334-336.

Hulin, B. T., Gabbett, T. J., Lawson, D. W., Caputi, P., \& Sampson, J. A. (2016). The acute: Chronicworkload ratio predicts injury: High chronic workload may decrease injury risk in elite rugby players. British Journal of Sports Medicine, 50, 231-236.

Impellizzeri, F. M., Rampinini, E., Coutts, A. J., Sassi, A., \& Marcora, S. M. (2004). Use of RPE-based training load in soccer. Medicine \& Science in Sports \& Exercise, 36, 1042-1047.

Jaspers, A., Brink, M. S., Probst, S. G., Frenken, W. G., \& Helsen, W. F. (2017). Relationships between training load indicators and training outcomes in professional soccer. Sports Medicine, 47, 533-544.

Jaspers, A., Kuyvenhoven, J. P., Staes, F., Frencken, W. G. P., Helsen, W. F., \& Brink, M. S. (2018). Examination of the external and internal load indicators association with overuse injuries in professional soccer players. Journal of Science and Medicine in Sport, 21, 579-585.
Jones, C. M., Griffiths, P. C., \& Mellalieu, S. D. (2017). Training load and fatigue marker associations with injury and illness: A systematic review of longitudinal studies. Sports Medicine, 47, 943-974.

Lu, D., Howle, K., Waterson, A., Duncan, C., \& Duffield, R. (2017). Workload profiles prior to injury in professional soccer players. Science and Medicine in Football, 3, 237-243.

Malone, S., Owen, A., Newton, M., Mendes, B., Collins, K. D., \& Gabbett, T. J. (2017). The acute: Chronicworkload ratio in relation to injury risk in professional soccer. Journal of Science and Medicine in Sport, 20, 561-565.

McCall, A., Carling, C., Michael, D., Nedelec, M., Le Gall, F., Berthoin, S., \& Dupont, G. (2014b). Injury risk factors, screening tests and preventative strategies: A systematic review of the evidence that underpins the perceptions and practices of 44 football (soccer) teams from various premier leagues. British Journal of Sports Medicine, 49, 583-589.

McCall, A., Carling, C., Nedelec, M., Davison, M., Le Gall, F., Berthoin, S., \& Dupont, G. (2014a). Risk factors, testing and preventative strategies for non-contact injuries in professional football: Current perceptions and practices of 44 teams from various premier leagues. British Journal of Sports Medicine, 49, 583-589.

Nilsson, T., Ostenberg, A. H., \& Alricsson, M. (2016). Injury profile among elite male youth soccer players in a Swedish first league. Journal of Exercise Rehabillitation, 12, 83-89.

Pfirrmann, D., Herbst, M., Ingelfinger, P., Perikles, S., \& Tug, S. (2016). Analysis of injury incidences in male professional adult and elite youth soccer players: A systematic review. Journal of Athletic Training, $51,410-424$.

Renshaw, A., \& Goodwin, P. C. (2016). Injury incidence in a Premier League youth soccer academy using the consensus statement: A prospective cohort study. British Medicine Journal Open Sport and Exercise Medicine, 2, e000132.

Salgueiro Da Silva, M. A., \& Seixas, T. M. (2017). The role of data range in linear regression. The Physics Teacher, 55, 371-372.

Saw, A. E., Main, L. C., \& Gastin, P. B. (2016). Monitoring the athlete training response: Subjective self-reported measures trump commonly used objective measures: A systematic review. British Journal of Sports Medicine, 50, 281-291.

van Mechelen, M., Hlobil, H., \& Kemper, H. C. (1992). Incidence, severity, aetiology and prevention of sports injuries. A Review of Concepts. Sports Medicine, 14, 82-89. 